\title{
Association between Postprocedural Infarction and Antiplatelet Drug Resistance after Coiling for Unruptured Intracranial Aneurysms
}

\author{
(D) M.S. Kim, (D) K.I. Jo, DJ.Y. Yeon, DJ.S. Kim, DK.H. Kim, DP. Jeon, and (D)S.C. Hong
}

\begin{abstract}
BACKGROUND AND PURPOSE: Procedure-related thromboembolism is a major limitation of coil embolization, but the relationship between thromboembolic infarction and antiplatelet resistance is poorly understood. The purpose of this study was to verify the association between immediate postprocedural thromboembolic infarction and antiplatelet drug resistance after endovascular coil embolization for unruptured intracranial aneurysm.
\end{abstract}

MATERIALS AND METHODS: This study included 338 aneurysms between October 2012 and March 2015. All patients underwent postprocedural MR imaging within 48 hours after endovascular coil embolization. Antiplatelet drug resistance was checked a day before the procedure by using the VerifyNow system. Abnormal antiplatelet response was defined as $>550$ aspirin response units and $>240$ P2Y12 receptor reaction units. In addition, we explored the optimal cutoff values of aspirin response units and P2Y12 receptor reaction units. The primary outcome was radiologic infarction based on postprocedural MR imaging.

RESULTS: Among 338 unruptured intracranial aneurysms, 134 (39.6\%) showed diffusion-positive lesions on postprocedural MR imaging, and 32 (9.5\%) and 105 (31.1\%) had abnormal aspirin response unit and P2Y12 receptor reaction unit values, respectively. Radiologic infarction was associated with advanced age (65 years and older, $P=.024$ ) only with defined abnormal antiplatelet response (aspirin response units $\geq 550, P 2 Y 12$ receptor reaction units $\geq 240)$. P2Y12 receptor reaction unit values in the top 10th percentile $(>294)$ were associated with radiologic infarction $(P=.003)$. With this cutoff value, age (adjusted odds ratio, 2.29; 95\% confidence interval, 1.28-4.08), P2Y12 receptor reaction units ( $>294 ;$ OR, 3.43; 95\% $\mathrm{Cl}, 1.53-7.71)$, and hyperlipidemia (OR, 2.05; $95 \% \mathrm{Cl}, 1.04-4.02)$ were associated with radiologic infarction in multivariate analysis.

CONCLUSIONS: Radiologic infarction after coiling for unruptured aneurysm was closely associated with age. Only very high P2Y12 receptor reaction unit values (>294) predicted postprocedural infarction. Further controlled studies are needed to determine the precise cutoff values, which could provide information regarding the optimal antiplatelet regimen for aneurysm coiling.

ABBREVIATIONS: $A R U$ = aspirin response unit; $D P L=$ diffusion-positive lesion; $P R U=$ P2Y12 receptor reaction unit

$\mathbf{E}^{\mathrm{n}}$ ndovascular coil embolization is a well-established treatment method for intracranial aneurysms. Recent evidence suggests that this procedure can be considered a first-line treatment for both ruptured and unruptured intracranial aneurysms. ${ }^{1,2}$ However, endovascular coil embolization still has major drawbacks, including procedural rupture, thromboembolic complications, and durability issues. Among these shortcomings, thromboembolism is

Received August 4, 2015; accepted after revision November 19.

From the Departments of Neurosurgery (M.S.K., J.Y.Y., J.S.K., S.C.H.) and Radiology (K.H.K., P.J.), Division of Interventional Neuroradiology, Samsung Medical Center, Sungkyunkwan University School of Medicine, Seoul, Korea; and Department of Neurosurgery (K.I.J.), Hana General Hospital, Cheongju, Korea.

Min Soo Kim and Kyung Il Jo contributed equally to this work.

Please address correspondence to Seung Chyul Hong, MD, Department of Neurosurgery, Samsung Medical Center, Sungkyunkwan University School of Medicine, 81 Irwon-ro, Gangnam-gu, Seoul 135-710, Korea; e-mail: nsschong@skku.edu

http://dx.doi.org/10.3174/ajnr.A4777 the most common problem. ${ }^{3-5}$ To reduce thromboembolic complications, many studies investigated the association between thromboembolism and aneurysm and/or patient factors. ${ }^{5-8}$ Previous studies have demonstrated that $30 \%-60 \%$ of endovascular coil embolizations for unruptured aneurysms show ischemic lesions on postprocedural diffusion-weighted images. Although most of the lesions seem to be benign, some could result in permanent neurologic sequelae. Recent studies demonstrated that antiplatelet resistance was associated with ischemic complications after coil embolization and that drug adjustment could lower the risk..$^{9,10}$ Still, these results are controversial, and the association between antiplatelet drug resistance and diffusion lesions has not yet been fully elucidated. ${ }^{11,12}$

Therefore, the purpose of this study was to verify the association between thromboembolic infarction and antiplatelet drug resistance after endovascular coil embolization for unruptured intracranial aneurysms. We also explored other risk factors for thromboembolic complications. 


\section{MATERIALS AND METHODS}

This retrospective study included patients from a data base prospectively collected between October 2012 and March 2015. This study was approved by the institutional review board, and informed consent was waived. During the given period, 470 unruptured aneurysms were treated in a single tertiary hospital. Among these, 129 cases were excluded due to lack of postprocedural MR imaging. There were no symptomatic infarctions among the excluded patients. Three cases with procedural rupture were also excluded, leaving 309 patients with 338 unruptured intracranial aneurysms for inclusion in this study.

Patient information, including sex, age, diabetes mellitus, hypertension, hyperlipidemia, smoking history, aneurysm profile including the size and location of the aneurysm, medical history, and pre- and postprocedural neurologic symptoms, was obtained from retrospective chart review. We also reviewed the number of angiograms obtained per intervention and total procedural time, which was considered to total anesthesia time.

Aneurysm size was categorized according to the long diameter on $3 \mathrm{D}$ digital subtraction angiography as small $(<7 \mathrm{~mm})$ and large ( $\geq 7 \mathrm{~mm}) .{ }^{13}$ Aneurysm location was categorized into internal carotid artery, anterior cerebral artery, middle cerebral artery, and posterior circulation systems. Postprocedural MR imaging was performed between 24 and 48 hours after the embolization procedure, and included diffusion-weighted imaging and timeof-flight (with 3D volume-rendered imaging). MRIs were reviewed by 2 independent board-certified radiologists. If hyperintense diffusion-positive lesions (DPLs) were detected on DWI, details of the lesions, including location, number, and size, were analyzed. The primary outcome of this study was the presence of DPL. Because there were only a small number $(n=2)$ of symptomatic lesions in this study population, we assumed that multiple lesions $(n \geq 6)$ were more severe lesions. ${ }^{5}$ Additionally, the degree of embolization was determined by immediate postprocedural MR imaging. ${ }^{14}$

\section{Antiplatelet Therapy and Antiplatelet Function Test}

Preprocedural antiplatelet therapy included aspirin $(100 \mathrm{mg})$ and clopidogrel $(75 \mathrm{mg}$ ) daily for 7 days before the elective endovascular coil embolization, regardless of stent usage. Response to the antiplatelet agents was evaluated in all patients the day before the procedure by using the VerifyNow P2Y12 assay (Accumetrics, San Diego, California). Because there was no definite evidence of association between antiplatelet drug resistance and immediate thromboembolic complications after coil embolization, the antiplatelet regimen was altered according to stent usage and the attending physician's discretion. An abnormal antiplatelet response was defined as $>550$ aspirin response units (ARUs) and/or $>240$ P2Y12 receptor reaction units (PRUs). ${ }^{15,16}$ Also, we tried to investigate and clarify the optimal cutoff values of both ARUs and PRUs that were associated with DPL, which have been controversial in the literature. ${ }^{11,17,18}$

\section{Coil Embolization Procedures}

Endovascular coil embolization was performed with the patient under general anesthesia. All procedures were performed by 2 neurointerventional experts at our center by using a biplane angiographic unit (Artis zee; Siemens, Erlangen, Germany). During the procedure, all patients were injected intravenously with heparin to prevent thromboembolic infarction. If thrombus was caused by using a catheter or wire during the procedure, the thrombus was immediately dissolved by using intravenous glycoprotein IIb/IIIa receptor inhibitor (tirofiban, Aggrastat), and the remission of the thrombus was confirmed with subsequent angiography. ${ }^{19}$ A bolus of intravenous heparin (60 IU/kg) was injected at the time of catheter insertion, and activated clotting times were assessed hourly. If the activated clotting time after heparinization was shorter than 2-3 times from the baseline, an additional 1000 IU of heparin was injected to maintain an acceptable activated clotting time throughout the procedure. In cases with stent-assisted coil embolization, heparinization was maintained until 24 hours postprocedure on the basis of activated partial thromboplastin time tests performed every 4 hours. In addition, although we mostly used the single-catheter technique, we recorded the use of multiple catheters because using an additional catheter was reported to increase the risk of thromboembolic complications during the procedure. ${ }^{20}$

\section{Statistical Analysis}

Statistical analyses were performed with SPSS, Version 22.0 (IBM, Armonk, New York); SAS, Version 9.4 (SAS Institute, Cary, North Carolina); and R Project Statistical and Computing software, R3.0.3 (http://www.R-project.org/). Univariate analysis was performed with the $\chi^{2}$, Fisher exact, and Student $t$ tests after dichotomizing patient clinical, laboratory, and procedural data. Variables with $P<.100$ in univariate analysis were chosen for multivariable models by using multivariate logistic regression models. Results of ARUs and PRUs were included in the multivariate analysis regardless of the results of univariate analysis because these were the variables of interest in this study. To explore the optimal cutoff values of ARUs and PRUs, we used a scatterplot to investigate the correlation among the ARU, PRU, and infarction event. We found that the ARU had no significant clinical correlation with an infarction event, whereas the PRU was significantly correlated. Thus, we divided the patients into 10 equal groups based on the PRU value used generally. In all analyses, $P \leq .05$ was statistically significant.

\section{RESULTS}

Baseline characteristics of patients are detailed in Table 1. Among 338 unruptured intracranial aneurysms, $263(77.8 \%)$ were small $(<7 \mathrm{~mm})$ and $75(22.2 \%)$ were large $(\geq 7 \mathrm{~mm})$. Stent-assisted embolization was performed in $148(43.8 \%)$ cases, and a multiple microcatheter technique was performed in 118 (34.9\%) cases. Antiplatelet function tests showed 32 (9.5\%) ARU abnormalities and 105 (31.1\%) PRU abnormalities. Complete embolization was achieved in $290(85.8 \%)$ cases based on postprocedural MR imaging. Mean total procedural time was $168 \pm 49$ minutes. Because lack of precise value of total procedure time, this value was excluded in multivariate analysis. The univariate analysis showed that total procedural time was significantly associated with DPL (DPL versus no DPL, $193 \pm 61$ minutes versus $166 \pm 48$ minutes; $P=.04)$. 
Table 1: Baseline patient characteristics according to antiplatelet resistance status

\begin{tabular}{|c|c|c|c|c|c|}
\hline & $\begin{array}{c}\text { Total } \\
(N=338)\end{array}$ & $\begin{array}{c}\text { Abnormal } \\
\text { ARU } \\
(n=32)\end{array}$ & $P$ Value $^{\mathrm{a}}$ & $\begin{array}{c}\text { Abnormal } \\
\text { PRU } \\
(n=105)\end{array}$ & $P$ Value $^{\mathrm{a}}$ \\
\hline \multicolumn{6}{|l|}{ Clinical } \\
\hline Age $(\geq 65 \mathrm{yr})$ & $204(60.4 \%)$ & $14(43.8 \%)$ & .061 & $33(31.4 \%)$ & .433 \\
\hline Sex (female) & $225(66.6 \%)$ & $23(71.9 \%)$ & .560 & $83(79.0 \%)$ & $.001^{\mathrm{b}}$ \\
\hline Diabetes & $23(6.8 \%)$ & $7(21.9 \%)$ & $.003^{b}$ & $11(10.5 \%)$ & .100 \\
\hline Hypertension & $146(43.2 \%)$ & $16(50.0 \%)$ & .456 & $48(45.7 \%)$ & .554 \\
\hline Hyperlipidemia & $53(15.7 \%)$ & $5(15.6 \%)$ & 1.000 & 12 (11.4\%) & .196 \\
\hline Smoking & 59 (17.5\%) & $5(15.6 \%)$ & .816 & $20(19.0 \%)$ & .643 \\
\hline TIA or stroke history & $16(4.7 \%)$ & $3(9.4 \%)$ & .381 & $3(2.9 \%)$ & .408 \\
\hline \multicolumn{6}{|l|}{ Procedure } \\
\hline $\begin{array}{l}\text { Dome size of aneurysm } \\
\quad \geq 7 \mathrm{~mm} \\
\text { Location of aneurysm }\end{array}$ & $75(22.2 \%)$ & $11(34.4 \%)$ & .114 & $28(26.7 \%)$ & .204 \\
\hline ICA & 198 (58.6\%) & $18(56.3 \%)$ & $.636^{\mathrm{c}}$ & $62(59.0 \%)$ & $.588^{c}$ \\
\hline MCA & $80(23.7 \%)$ & $11(34.4 \%)$ & & $20(19.0 \%)$ & \\
\hline ACA & $28(8.3 \%)$ & $1(3.1 \%)$ & & $12(11.4 \%)$ & \\
\hline Posterior circulation & $32(9.5 \%)$ & $2(6.3 \%)$ & & $11(10.5 \%)$ & \\
\hline \multicolumn{6}{|l|}{ Technique } \\
\hline Assist with stent & 149 (44.1\%) & $14(43.8 \%)$ & 1.000 & 45 (42.9\%) & .813 \\
\hline Double catheter & $116(34.3 \%)$ & $14(43.8 \%)$ & .246 & $42(40.0 \%)$ & .173 \\
\hline Incomplete occlusion & 48 (14.2\%) & $4(12.5 \%)$ & .804 & $18(17.1 \%)$ & .315 \\
\hline Thrombus formation & $5(1.5 \%)$ & $2(6.3 \%)$ & .073 & $2(1.9 \%)$ & 1.000 \\
\hline $\begin{array}{c}\text { Mean No. of angiograms } \\
\pm S D\end{array}$ & $6.87 \pm 2.34$ & $6.53 \pm 1.93$ & .386 & $7.17 \pm 2.36$ & .115 \\
\hline
\end{tabular}

Note:-ACA indicates anterior cerebral artery.

${ }^{a} P$ value was obtained by comparing patients with normal response with a $\chi^{2}$. Fischer exact, or Student $t$ test for each variable.

b Significant.

'These values were obtained by comparing ICA versus MCA, ACA, or posterior circulation with linear-by-linear association.

Comparisons between the normal and abnormal antiplatelet response groups showed that diabetes was more frequent in the abnormal ARU group, while the abnormal PRU group showed a higher female/male ratio. No other variables showed a statistically significant difference between groups (Table 1).

Of 338 cases, 134 (39.6\%) showed DPLs on postprocedural MR imaging. Among cases with a DPL, 89 had ipsilateral lesions, 16 had contralateral lesions, and 29 had both ipsilateral and contralateral lesions. One hundred twenty-one cases (90.3\%) were small-dot $(<15 \mathrm{~mm})$ lesions, and 13 cases $(9.7 \%)$ had large $(>15$ $\mathrm{mm})$ lesions. Twenty-nine cases had multiple $(\geq 6)$ lesions on postprocedural DWI. There were no territorial infarctions in this study population. Thrombus formation during the procedure occurred in 5 patients, and they received intravenous tirofiban immediately. None of the patients with procedural thrombus formation showed neurologic deterioration.

Only 2 patients showed neurologic deficits associated with ischemic lesions on postprocedural MR imaging. One patient showed only an abnormal ARU value, and the other patient showed normal ARU and PRU values. One patient had a persistent deficit despite improvement (Fig 1), while the other patient experienced a full recovery (Fig 2).

\section{Any Diffusion-Positive Lesion}

Univariate analyses showed that advanced age (65 years or older) $(P=.006)$, incomplete occlusion $(P=.016)$, and dome size of the aneurysm $(\geq 7 \mathrm{~mm})(P=.016)$ were associated with the presence of a DPL $(P<.05)$. However, ARU $(P=.448)$ and PRU $(P=$ .337) abnormalities were not associated with DPL in this data- set $(P>.05)$. According to multivariate logistic regression analysis, advanced age (65 years or older; $P=$ .024; OR, 1.78; 95\% confidence interval, 1.08-2.93) was associated with the presence of a DPL $(P<.05)$. Detailed statistical results are described in Table 2.

\section{Multiple Diffusion-Positive Lesions (n $\geq 6$ )}

Advanced age (65 years or older) $(P=$ $.017)$, incomplete occlusion $(P=.033)$, and large aneurysm size $(\geq 7 \mathrm{~mm})(P=$ $.012)$ were associated with multiple DPLs. ARU $(P=.215)$ and PRU $(P=$ .399) abnormalities were not associated with multiple ( $\geq 6$ ) DPLs. Multivariate analysis showed that advanced age (65 years or older $)(P=.030$; OR, $2.47 ; 95 \%$ CI, 1.09-5.59), incomplete occlusion $(P=.039 ;$ OR, 2.66; 95\% CI, 1.05-6.76), and thrombus formation $(P=.010$; OR, 9.93; 95\% CI, 1.86-97.10) were associated with multiple DPLs $(P<.05)$.

\section{Optimal Cutoff Value of Antiplatelet Resistance}

DPLs were not associated with ARUs by scatterplot (Fig 3). The number of infarctions tended to increase along with PRU values but did not show statistical significance ( $P=.090$; estimated OR, $1.00 ; 95 \%$ CI, 1.00-1.01; Fig 3). PRU values in the top $10 \%(>294)$ were associated with DPLs $(P=.003$; OR, 4.8; 95\% CI, 1.71-13.50; Fig 4$)$. With this cutoff value, advanced age (65 years or older) (OR, 2.29; 95\% CI, 1.28-4.08), PRU ( $\geq 294$ ) (OR, 3.43; 95\% CI, 1.53-7.71), and hyperlipidemia (OR, 2.05; 95\% CI, 1.04-4.02) were associated with DPL in multivariate analysis.

\section{DISCUSSION}

Recent studies have demonstrated that high-on-treatment platelet reactivity was associated with symptomatic infarction and an increased the risk of mortality. ${ }^{11,21,22}$ However, patients in these studies regarding antiplatelet resistance were mostly those with atherosclerotic steno-occlusive disease, especially in cardiointerventions. ${ }^{23,24}$ Unlike atherosclerotic vessels, unruptured aneurysms do not always cause significant atherosclerotic burden. High-on-treatment platelet reactivity should be individualized by receiver operating characteristics; therefore, different conclusions can be drawn from previous studies.

Several studies support the idea that clopidogrel resistance can increase postprocedural thromboembolic complications, and our preliminary study showed similar results. ${ }^{4,11,12,22}$ Hwang et al ${ }^{10}$ recently reported that abnormal PRUs were associated with symptomatic infarction and that modified antiplatelet preparation could reduce the rate of thromboembolic events in coil embolization. In contrast, in this study, the occurrence of immediate 

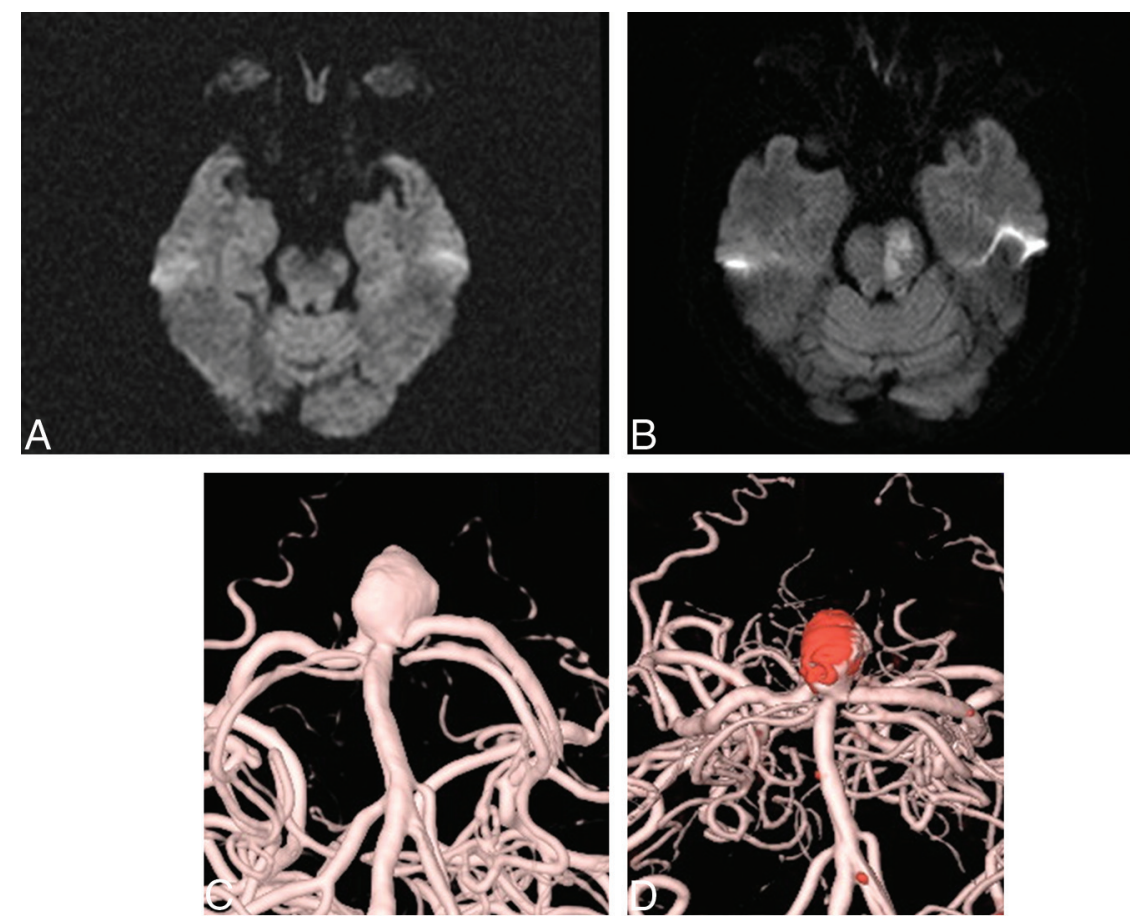

FIG 1. A 75-year-old woman with a 10.81-mm basilar tip aneurysm underwent endovascular coil embolization. A, Preprocedural MR imaging (DWI). B, Postprocedural MR imaging (DWI). C, Preprocedural angiography. $D$, Postprocedural angiography.
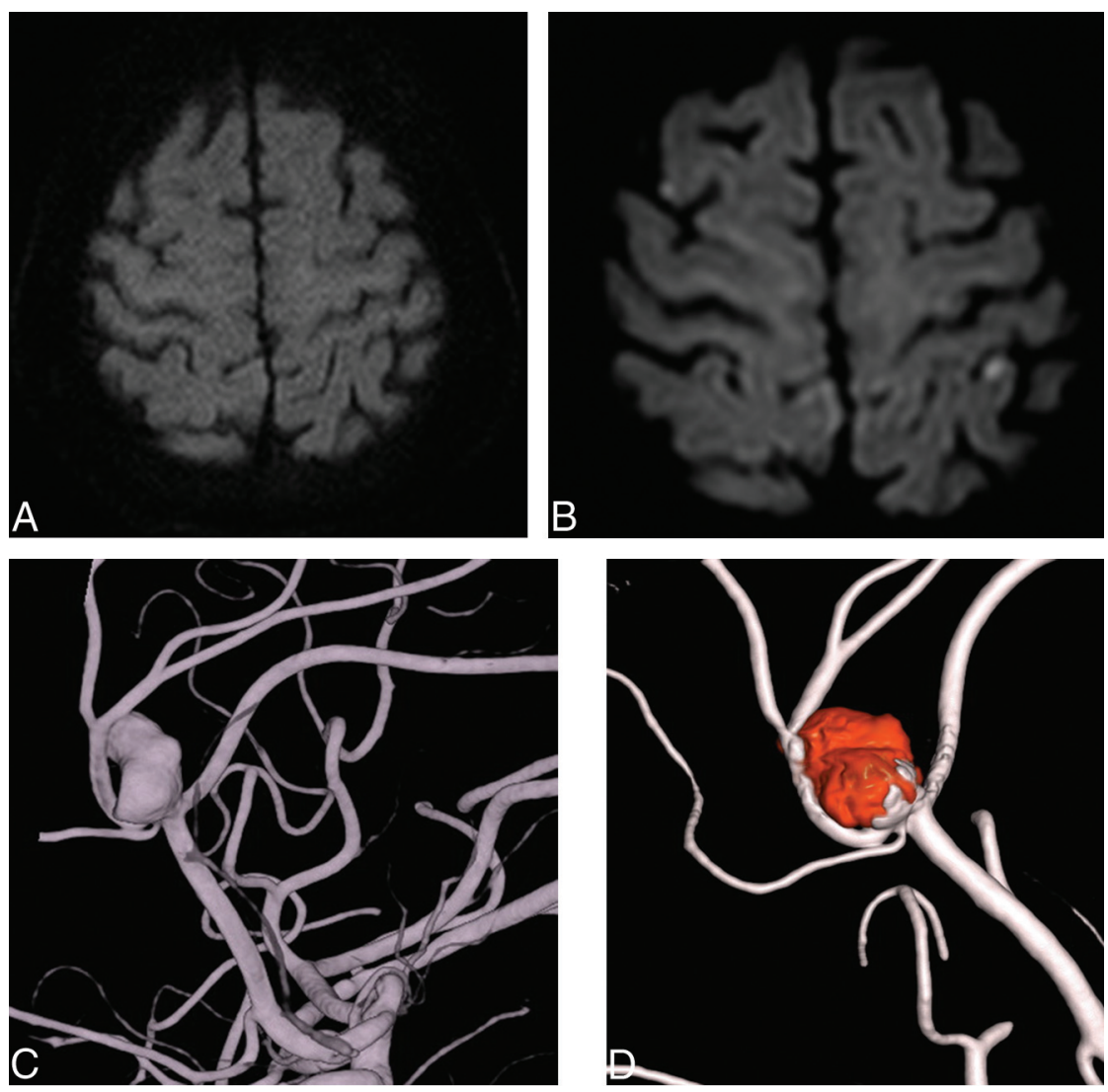

FIG 2. A 71-year-old woman with an aneurysm with a maximal diameter of $12.32 \mathrm{~mm}$ on the $A 2 / 3$ segment. A, Preprocedural MR imaging (DWI). B, Postprocedural MR imaging (DWI). C, Preprocedural angiography. $D$, Postprocedural angiography. postprocedural thromboembolic infarction was not closely associated with antiplatelet hyporesponders. This disparity is likely the result of different definitions of abnormal antiplatelet response and different outcome measurements because the PRU cutoff value varied widely among studies. ${ }^{4,10,11}$ Our results showed that abnormal PRUs (>240) were not associated with DPL, but PRU values in the upper 10th percentile (>294) were associated with DPL. These different results suggest that only nonresponse is associated with a higher thromboembolic risk.

Different outcome-measurement approaches could be another source of the contradictory results. Hwang et $\mathrm{al}^{10}$ used symptomatic infarction and procedural thrombus formation as the primary outcome. In this study, the primary outcome was the presence of a diffusion-positive lesion rather than symptomatic infarction because there were only 2 cases of symptomatic infarction in this case series. Instead, multiple $(\geq 6)$ small-dot lesions were categorized, and the association with variables was studied because multiple ( $\geq 6$ ) smalldot lesions on immediate postprocedural MR imaging were closely associated with symptomatic infarction in a previous study. ${ }^{7}$ We hypothesized that image-guided analysis would be more objective and that the possibility of missing a thromboembolic event would be lower. If a patient had a silent infarction, his or her death could be confused with that of a patient without complications.

A previous study showed that advanced age (65 years or older) was the only predictor of diffusion lesions after coil embolization. The authors suggested that tortuous vascular structures and underlying atherosclerotic burden could cause these results. ${ }^{8}$ Our findings support the findings of this previous study. Almekhlafi et $\mathrm{al}^{25}$ reported that during carotid artery stent placement, microemboli could occur during stent deployment or advancement through the stenosis. Thromboembolic complications could occur by dislodging thrombi from atherosclerotic vessels proximal to the target site and cracking the atherosclerotic plaque. ${ }^{12}$ Therefore, the use of wires or a catheter at the target site would cause thromboembolic 
Table 2: Patient clinical, laboratory, and procedural variables associated with any DPL and multiple DPLs ( $\geq 6$ ) on univariate and multivariate logistic analyses

\begin{tabular}{|c|c|c|c|c|c|c|}
\hline & \multicolumn{3}{|c|}{ Any DPL } & \multicolumn{3}{|c|}{$\mathrm{DPL} \geq 6$} \\
\hline & $\begin{array}{c}\text { Univariate } \\
\text { ( } P \text { Value) }\end{array}$ & $\begin{array}{c}\text { Multivariate } \\
\text { ( } P \text { Value) }\end{array}$ & $\begin{array}{c}\text { OR } \\
(95 \% \mathrm{Cl}) \\
\end{array}$ & $\begin{array}{c}\text { Univariate } \\
\text { ( } P \text { Value) }\end{array}$ & $\begin{array}{c}\text { Multivariate } \\
\text { ( } P \text { Value) }\end{array}$ & $\begin{array}{c}\text { OR } \\
(95 \% \mathrm{Cl}) \\
\end{array}$ \\
\hline \multicolumn{7}{|l|}{ Clinical } \\
\hline Age ( $\geq 65 \mathrm{yr})$ & .006 & .024 & $1.78(1.08-2.93)$ & .017 & .030 & $2.47(1.09-5.59)$ \\
\hline Sex (female) & .556 & & & .309 & & \\
\hline Diabetes & .508 & & & .123 & & \\
\hline Hypertension & .502 & & & .239 & & \\
\hline Hyperlipidemia & .092 & .065 & $1.76(0.97-3.27)$ & 1.000 & & \\
\hline Smoking & .884 & & & .327 & & \\
\hline TIA or stroke history & 1.000 & & & .149 & & \\
\hline \multicolumn{7}{|l|}{ Laboratory } \\
\hline $\operatorname{ARU}(\geq 550)$ & .448 & .802 & $1.11(0.51-2.41)$ & .755 & .215 & $0.33(0.06-1.90)$ \\
\hline $\operatorname{PRU}(>240)$ & .337 & .357 & $1.23(0.76-2.01)$ & .294 & .399 & $1.42(0.63-3.20)$ \\
\hline \multicolumn{7}{|l|}{ Procedure } \\
\hline Dome size of aneurysm $\geq 7 \mathrm{~mm}$ & .016 & .112 & $1.57(0.90-2.74)$ & .033 & .267 & $1.65(0.68-3.99)$ \\
\hline Location of aneurysm & .111 & & & .551 & & \\
\hline \multicolumn{7}{|l|}{ Technique } \\
\hline Assist with stent & .145 & & & .437 & & \\
\hline Multiple catheters & 1.000 & & & .418 & & \\
\hline Incomplete occlusion & .016 & .085 & $1.78(0.92-3.44)$ & .012 & .039 & $2.66(1.05-6.76)$ \\
\hline Thrombus formation & .083 & .082 & $7.32(0.78-69.24)$ & .060 & .010 & $9.93(1.86-97.10)$ \\
\hline No. of angiograms & .341 & & & .954 & & \\
\hline
\end{tabular}
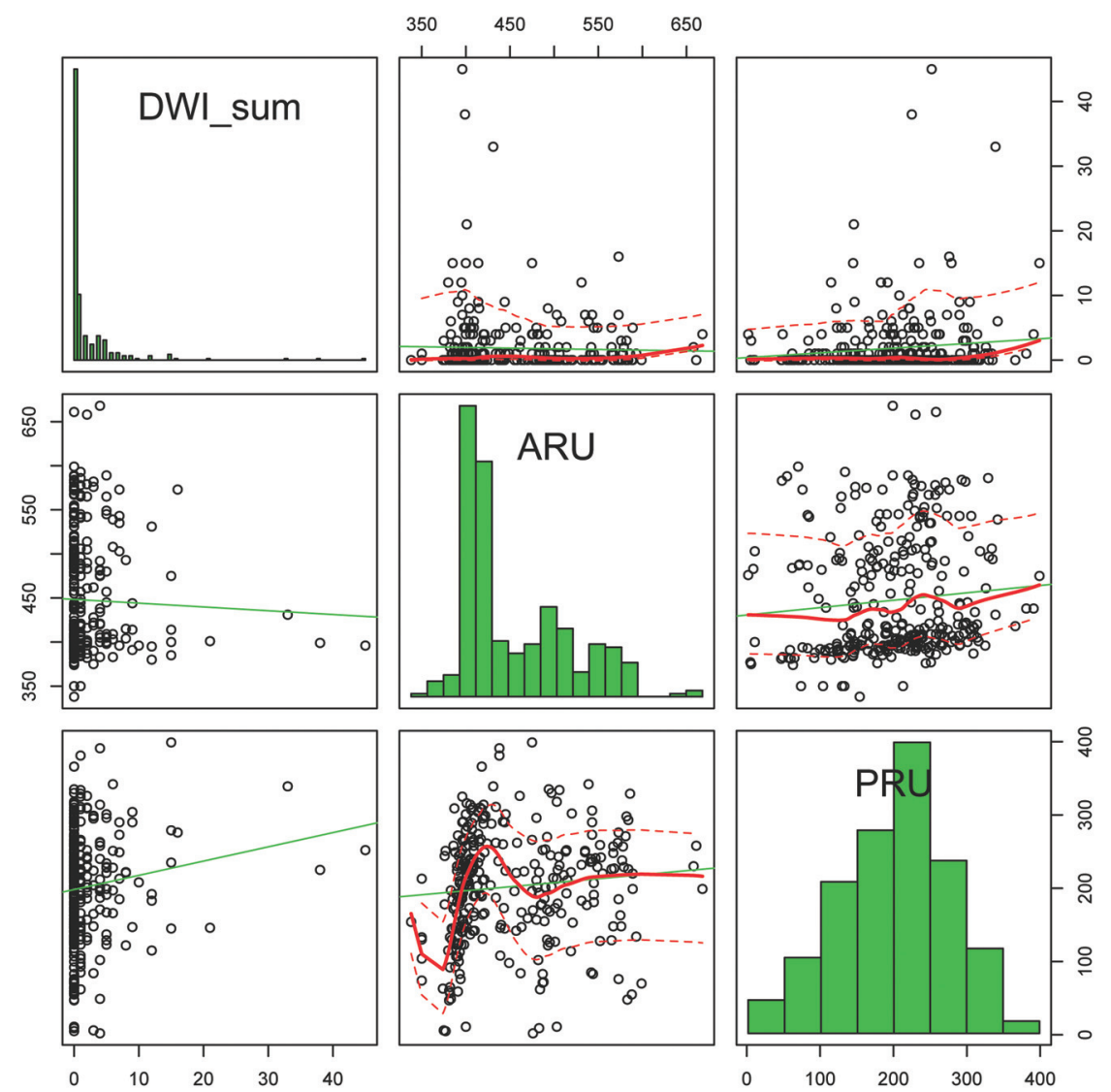

FIG 3. A scatterplot shows that the number of infarctions tends to increase along with PRU. ARU did not show a similar tendency.

events by dislodging thrombi from the atherosclerotic vessels at the aortic arch level. In this situation, nonipsilateral DPL occurred after the procedure. However, there are no data regarding the degree of atherosclerosis and tortuosity of the aortic arch.
For further evaluation and to identify the source of thromboembolism during coiling, CT angiography including the aortic arch could be helpful. Softer and smaller caliber catheters and wires and more skillful techniques could reduce the chance of dislodging thrombi during the procedure. Hwang et $\mathrm{al}^{26}$ reported that incomplete occlusion is a risk factor for delayed ischemic stroke due to induced blood flow disturbance or stagnation. This study suggests that incomplete occlusion could be a source of infarction in both immediate and delayed thromboembolism. In addition, incomplete occlusion and large aneurysm size could explain frequent thromboembolism due to struggling to achieve complete occlusion of an aneurysm. These attempts could prolong the duration of procedure. ${ }^{20,27}$ Therefore, increased procedural time could possibly lead to thromboembolic complications in the postprocedural period. Mani and Eisenberg ${ }^{28}$ reported that the thromboembolic complication rate increases when the arteriographic procedure exceeds 80 minutes. Our study also showed that procedural time was associated with postprocedural DPL.

The 5 patients experiencing thrombus formation during the procedure had variable aneurysm diameters, neck sizes, and antiplatelet resistance. Among these patients, 4 had asymptomatic DPLs on postprocedural MR imaging and 1 showed no DPL or symptoms. Although thrombus formation during the procedure showed a statistically significant difference on multiple $(\geq 6)$ DPLs in mul- 


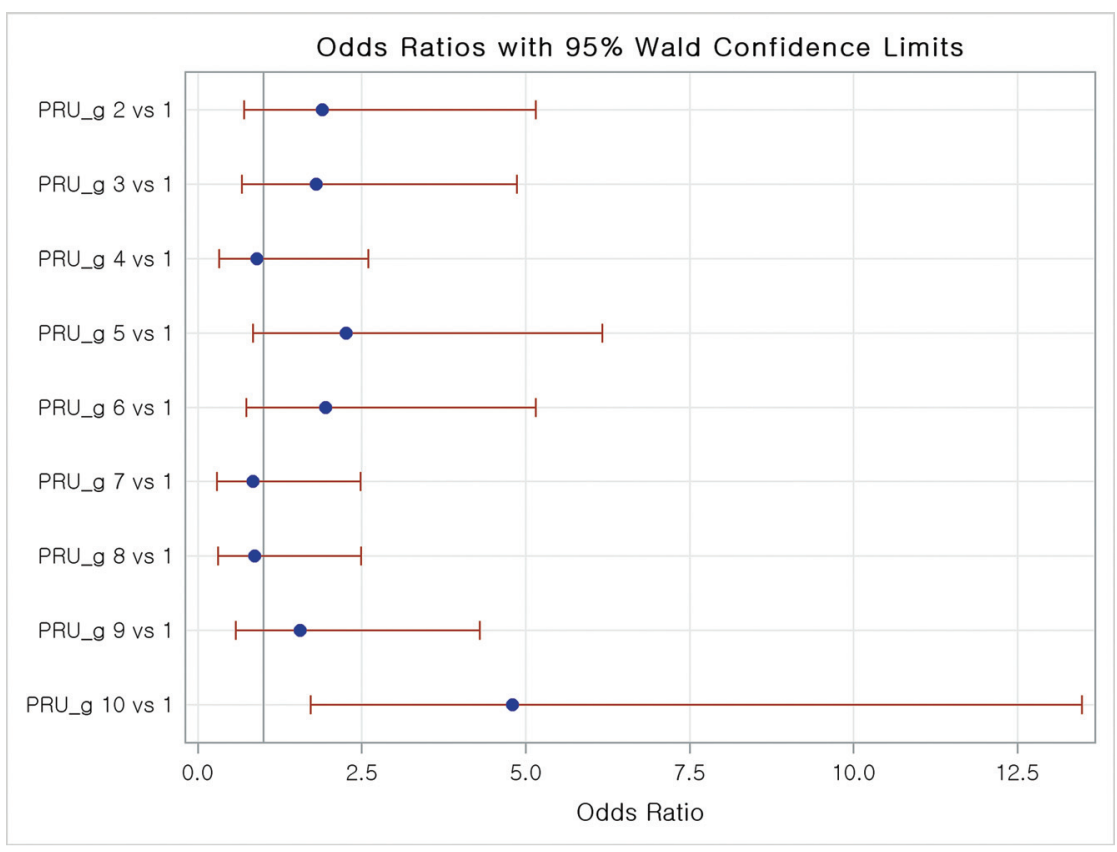

FIG 4. Association between PRU values and diffusion-positive lesions. The top $10 \%$ of PRU values $(>294)$ were associated with higher thromboembolic risk $(P=.0029)$. include the number of angiograms obtained per intervention in multivariate analysis because they were associated with DPL in univariate analysis. Procedural time could be a potential predictor of DPL because it relates to the difficulty of coil embolization. These variables could be potential predictors of postprocedural DPL and could be considered important variables in further study.

\section{CONCLUSIONS}

Postprocedural DPL was closely associated with advanced age. Only clopidogrel nonresponse (PRU >294) could predict DPL after unruptured aneurysm coiling. The antiplatelet regimen should be individualized on the basis of the receiver operating characteristics. Further studies are needed to determine precise cutoff values, which may provide a rationale for the optimal antiplatelet regimen for aneurysm coiling. tivariate logistic regression analysis, thrombus formation during embolization of unruptured aneurysm seems to be benign with the appropriate usage of a glycoprotein IIb/IIIa inhibitor.

\section{Limitations}

Several limitations of this study should be noted. First, although this study uses prospectively collected data, patient data were obtained from retrospective chart review. Therefore, minimal, transient symptoms could be missed in this analysis. Second, this study did not include the effect of systemic heparinization during the procedure. Despite maintaining heparinization during the procedure, precise activated clotting time control was difficult due to various patient responses to injected heparin. Third, the primary outcome of this study was DPL rather than symptomatic infarction. Although we hypothesized that image-based analysis could be more objective, these data may not have clinical significance. Fourth, these data were analyzed at an aneurysm level due to classification difficulties. Difficulties occurred when an individual patient had multiple aneurysms. Analyzing the patient at an aneurysm level prevents such difficulties because the individual aneurysms are checked into the data base separately. Additionally, we analyzed the data at a patient level and found that there were no significant differences in the patient-level clustering data results.

Last, some experts recommended analyzing the clinical association with procedural time, the number of angiograms performed per intervention, and DPL. ${ }^{20,29-31}$ The exact time of each procedure was not included in our registry data base. According to our retrospective chart review, we could only obtain anesthesia time, not procedural time. The univariate analysis revealed that anesthesia time was solely associated with DPL but not the number of angiograms performed per intervention. However, anesthesia time could different from procedure time due to other procedure time associated with anesthesia. Therefore, we did not include total procedural time in multivariate analysis. In addition, we did not

\section{REFERENCES}

1. Ruan C, Long H, Sun $H$, et al. Endovascular coiling vs. surgical clipping for unruptured intracranial aneurysm: a meta-analysis. Br J Neurosurg 2015;29:485-92 CrossRef Medline

2. Norback O, Gál G, Johansson M, et al. The establishment of endovascular aneurysm coiling at a neurovascular unit: report of experience during early years. Neuroradiology 2005;47:144-52 CrossRef Medline

3. Rahme RJ, Zammar SG, El Ahmadieh TY, et al. The role of antiplatelet therapy in aneurysm coiling. Neurol Res 2014;36:383-88 CrossRef Medline

4. Kim B, Kim K, Jeon P, et al. Thromboembolic complications in patients with clopidogrel resistance after coil embolization for unruptured intracranial aneurysms. AJNR Am J Neuroradiol 2014;35: 1786-92 CrossRef Medline

5. Kang DH, Kim BM, Kim DJ, et al. MR-DWI-positive lesions and symptomatic ischemic complications after coiling of unruptured intracranial aneurysms. Stroke 2013;44:789-91 CrossRef Medline

6. Hahnemann ML, Ringelstein A, Sandalcioglu IE, et al. Silent embolism after stent-assisted coiling of cerebral aneurysms: diffusionweighted MRI study of 75 cases. J Neurointerv Surg 2014;6:461-65 CrossRef Medline

7. Cronqvist M, Wirestam R, Ramgren B, et al. Diffusion and perfusion MRI in patients with ruptured and unruptured intracranial aneurysms treated by endovascular coiling: complications, procedural results, MR findings and clinical outcome. Neuroradiology 2005;47: 855-73 CrossRef Medline

8. Soeda A, Sakai N, Sakai H, et al. Thromboembolic events associated with Guglielmi detachable coil embolization of asymptomatic cerebral aneurysms: evaluation of 66 consecutive cases with use of diffusion-weighted MR imaging. AJNR Am J Neuroradiol 2003;24: 127-32 Medline

9. Oxley TJ, Dowling RJ, Mitchell PJ, et al. Antiplatelet resistance and thromboembolic complications in neurointerventional procedures. Front Neurol 2011;2:83 CrossRef Medline

10. Hwang G, Huh W, Lee JS, et al. Standard vs modified antiplatelet preparation for preventing thromboembolic events in patients with high on-treatment platelet reactivity undergoing coil embolization for an unruptured intracranial aneurysm: a randomized clinical trial. JAMA Neurol 2015;72:764-72 CrossRef Medline 
11. Kang HS, Kwon BJ, Kim JE, et al. Preinterventional clopidogrel response variability for coil embolization of intracranial aneurysms: clinical implications. AJNR Am J Neuroradiol 2010;31:1206-10 CrossRef Medline

12. Kim BJ, Kwon JY, Jung JM, et al. Association between silent embolic cerebral infarction and continuous increase of P2Y12 reaction units after neurovascular stenting. J Neurosurg 2014;121:891-98 CrossRef Medline

13. Wiebers DO, Whisnant JP, Huston J 3rd, et al; International Study of Unruptured Intracranial Aneurysms Investigators. Unruptured intracranial aneurysms: natural history, clinical outcome, and risks of surgical and endovascular treatment. Lancet 2003;362:103-10 CrossRef Medline

14. Ernst M, Yoo AJ, Kriston L, et al. Is visual evaluation of aneurysm coiling a reliable study end point? Systematic review and metaanalysis. Stroke 2015;46:1574-81 CrossRef Medline

15. Delgado Almandoz JE, Crandall BM, Scholz JM, et al. Pre-procedure P2Y12 reaction units value predicts perioperative thromboembolic and hemorrhagic complications in patients with cerebral aneurysms treated with the Pipeline Embolization Device. J Neurointerv Surg 2013;5(suppl 3):iii3-10 CrossRef Medline

16. Maruyama H, Takeda H, Dembo T, et al. Clopidogrel resistance and the effect of combination cilostazol in patients with ischemic stroke or carotid artery stenting using the VerifyNow P2Y12 assay. Intern Med 2011;50:695-98 CrossRef Medline

17. Godino C, Mendolicchio L, Figini F, et al. Comparison of VerifyNow-P2Y12 test and flow cytometry for monitoring individual platelet response to clopidogrel: what is the cut-off value for identifying patients who are low responders to clopidogrel therapy? Thromb J 2009;7:4 CrossRef Medline

18. Park KW, Park JJ, Jeon KH, et al. Clinical predictors of high posttreatment platelet reactivity to clopidogrel in Koreans. Cardiovasc Ther 2012;30:5-11 CrossRef Medline

19. Jeon JS, Sheen SH, Hwang G, et al. Intraarterial tirofiban thrombolysis for thromboembolisms during coil embolization for ruptured intracranial aneurysms. J Cerebrovasc Endovasc Neurosurg 2012;14: 5-10 CrossRef Medline

20. Bendszus M, Koltzenburg M, Burger R, et al. Silent embolism in diagnostic cerebral angiography and neurointerventional procedures: a prospective study. Lancet 1999;354:1594-07 CrossRef Medline

21. Ozben S, Ozben B, Tanrikulu AM, et al. Aspirin resistance in pa- tients with acute ischemic stroke. J Neurol 2011;258:1979-86 CrossRef Medline

22. Yamada NK, Cross DT 3rd, Pilgram TK, et al. Effect of antiplatelet therapy on thromboembolic complications of elective coil embolization of cerebral aneurysms. AJNR Am J Neuroradiol 2007;28: 1778-82 CrossRef Medline

23. Lev EI, Patel RT, Maresh KJ, et al. Aspirin and clopidogrel drug response in patients undergoing percutaneous coronary intervention: the role of dual drug resistance. J Am Coll Cardiol 2006;47:27-33 CrossRef Medline

24. Saw J, Densem C, Walsh S, et al. The effects of aspirin and clopidogrel response on myonecrosis after percutaneous coronary intervention: a BRIEF-PCI (Brief Infusion of Intravenous Eptifibatide Following Successful Percutaneous Coronary Intervention) trial substudy. JACC Cardiovasc Interv 2008;1:654-59 CrossRef Medline

25. Almekhlafi MA, Demchuk AM, Mishra S, et al. Malignant emboli on transcranial Doppler during carotid stenting predict postprocedure diffusion-weighted imaging lesions. Stroke 2013;44:1317-22 CrossRef Medline

26. Hwang G, Kim JG, Song KS, et al. Delayed ischemic stroke after stent-assisted coil placement in cerebral aneurysm: characteristics and optimal duration of preventative dual antiplatelet therapy. $R a$ diology 2014;273:194-201 CrossRef Medline

27. Dion JE, Gates PC, Fox AJ, et al. Clinical events following neuroangiography: a prospective study. Stroke 1987;18:997-1004 CrossRef Medline

28. Mani RL, Eisenberg RL. Complications of catheter cerebral arteriography: analysis of 5,000 procedures, III: assessment of arteries injected, contrast medium used, duration of procedure, and age of patient. AJR Am J Roentgenol 1978;131:871-74 CrossRef Medline

29. Kato K, Tomura N, Takahashi S, et al. Ischemic lesions related to cerebral angiography: evaluation by diffusion weighted MR imaging. Neuroradiology 2003;45:39-43 Medline

30. Britt PM, Heiserman JE, Snider RM, et al. Incidence of postangiographic abnormalities revealed by diffusion-weighted MR imaging. AJNR Am J Neuroradiol 2000;21:55-59 Medline

31. Hähnel S, Bender J, Jansen O, et al. Clinically silent cerebral embolisms after cerebral catheter angiography [in German]. Rofo 2001; 173:300-05 CrossRef Medline 